\title{
Predictive Management of Fire Risks in Building
}

\author{
Sanae KHALI ISSA \\ Laboratory of Sciences \\ Computer, Systems and \\ Telecommunication \\ (LIST)Faculty of Science and \\ Technology (FST), Tangier, \\ Morocco
}

\author{
Abdellah AZMANI \\ Laboratory of Sciences \\ Computer, Systems and \\ Telecommunication (LIST) \\ Faculty of Science and \\ Technology (FST), Tangier, \\ Morocco
}

\author{
Karima ZEJLI \\ Laboratory of mechanics and \\ physics of heterogeneous \\ environment (LMPH), \\ Faculty of Science and \\ Technology (FST), Tangier, \\ Morocco
}

\begin{abstract}
This paper presents a method for forward management of buildings fire risks. This method combines artificial intelligence and probability through the use of Bayesian Networks.
\end{abstract}

\section{General terms}

Bayesian Networks, DecisionMaking, artificial intelligence, fire security.

\section{Keywords}

Prediction, Bayesian networks, fire.

\section{INTRODUCTION}

Buildings are often the scene of serious accidents such as floods, fires, gas leaks caused voluntarily or involuntarily.

These accidents, domestic accidents called, they not only represent a major causeof permanent invalidity, mortality and morbiditybut they also caused serious health problems, especially for young, old and sick people.

The risk of these accidents increases due of their effects and their influences [1][2]. For example, fire accidents and gas leaks are the most dangerous because they can propagate throughout the building.

In this paper, we propose a method to contribute to design a model that can be integrated into a smart computer system [3] to prevent against fire risks in an edifice through the identification, quantification and analysis of potential sources that may cause a fire's departure or its expansion. This model must also consider the presence of factors that may reduce the eventual consequences.

The main objective of our method is to design a decisional system incorporating an expert system able to audit the risks incurred by an existing building or helping architects and builders to better reflect the potential risks during the construction of a building.

The home fires are influenced by many factors and constraints:

- The building architecture.

- Building materials (degree of inflammation, degree of toxicity etc.).

- Number of the people present in building (density of people within a zone or $\mathrm{m}^{2}$ )
Many methods can be applied in this area,in this paper, we present a method based on Bayesian networks.

\section{PROPOSITION OF A PROCESS CONTROL APLICATIONS}

\subsection{Objectives}

The aim of our work is to create tools using SaaS[4] in Full Web applications that can provide tangible assistance for the building sectorand the fire department.

This will result in the creation of a tool for decision support system involving a multi-expert systems [5][6] based according to the relevance of the application context of various techniques such as Bayesian networks, fuzzy logic, constraint programming and learning techniques and others, in order to help professionals :

- To design a building incorporating technological elements related to materials and means of ICT.

- To anticipate risks and make predictions on different spatial and temporal events.

- To manage new hazardous situations (use of different sensors and their coupling with the ICT resources in order to be alerted andto provide real-time monitoring).

\subsection{Principle of ourconcept}

Our idea is to combine artificial intelligence and statistics, using Bayesian networks [7] [8] [9] to develop a predictive diagnostic fire according to the following process.

1. Identify the fireparameters.

2. Attribute probability coefficients for each parameter.

3. Establish a diagnostic for the results obtained by using the Bayes method.

4. Suggest a defense method against fire.

5. Application of learning technology for automatic correction.

\subsection{Danger process of fire}

Before starting to identify the parameters which influence the fire problems, it appeared essential to know the danger fire process [10][11]. 


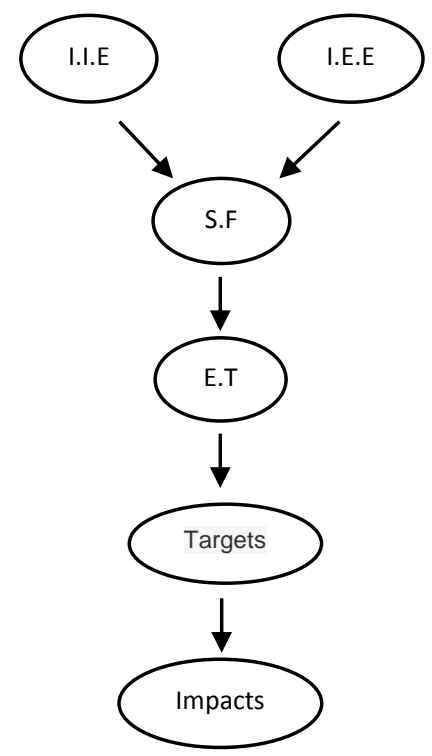

Fig. 1: Danger fire process

I.I.E : Initial Internal Events

I.E.E : Initial External Events

S.F : Source of Fire

E.T : Events terminals

\subsection{Parameter identification}

The building can be represented as a dynamic system related to the fire, in this perspective, we propose two modeling approaches that can be established.

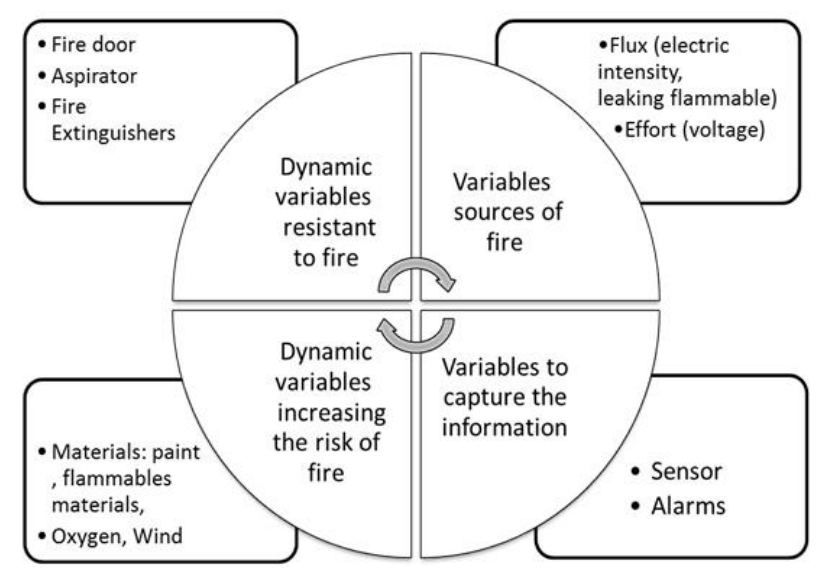

Fig. 2: Fire parameters

The various factors that could cause a fire are grouped in the following table:
Table 1: Attribution of probability coefficients depending on the category of factors causing a fire

\begin{tabular}{|c|c|c|}
\hline Trigger & Description & Probability \\
\hline Criminalact & $\begin{array}{ll}\checkmark & \text { Pyromaniac } \\
\checkmark & \text { Terrorist } \\
\checkmark & \text { Revenge } \\
\checkmark & \text { Child who sets fire to a } \\
& \text { flammable material }\end{array}$ & $\begin{array}{l}\text { From } 80 \\
\text { to } 90 \%\end{array}$ \\
\hline $\begin{array}{c}\text { Involontaryhuma } \\
\text { nact }\end{array}$ & $\begin{array}{ll}\checkmark & \text { Smoldering cigarette } \\
\checkmark & \text { stove Flames } \\
\checkmark & \text { Mishandling of } \\
& \text { commercial products } \\
& \text { labeled dangerous, } \\
& \text { toxic, corrosive, } \\
& \text { flammable liquids, } \\
& \text { flammable solids, } \\
& \text { oxidizers, explosives, } \\
& \text { or produce flammable } \\
& \text { gas on contact with } \\
& \text { water } \\
\checkmark & \text { Ignorance which } \\
\text { induces dangerous } \\
\text { mixtures of chemicals. } \\
\checkmark & \text { Bad installations or } \\
\text { absence of } \\
\text { maintenance } \\
\checkmark \\
\text { Candles lighted in } \\
\text { front of flammable } \\
\text { objects } \\
\text { Child playing with } \\
\text { matches, a lighter ... }\end{array}$ & $\begin{array}{l}\text { From } 20 \\
\text { to } 40 \%\end{array}$ \\
\hline Poor Installation & $\begin{array}{ll}\checkmark & \text { Overload } \\
\checkmark & \text { Short circuits } \\
\checkmark & \text { Multiplication of } \\
& \text { devices. } \\
\checkmark & \text { Overflow of the } \\
& \text { electrical circuit }\end{array}$ & $\begin{array}{l}\text { From } 20 \\
\text { to } 40 \%\end{array}$ \\
\hline Poor Equipment & $\begin{array}{ll}\checkmark & \text { LowQuality } \\
\checkmark & \text { Use of bad son electric } \\
\checkmark & \text { Bad Use of } \\
\text { - } & \text { Heating to dry } \\
& \text { clothes } \\
\text { - } & \text { Oven to heat a } \\
& \text { room } \\
\text { - } & \text { Hairdryer lit next } \\
& \text { to a flammable } \\
& \text { material } \\
\text { - } & \text { Clothing Iron } \\
& \text { placed on a } \\
& \text { flammable } \\
& \text { material. } \\
\text { - } & \text { Missed a pot on the } \\
& \text { fire } \\
\text { Présence de défaillance } \\
\text { - Housekeeping } \\
\text { - } \text { home } \\
\text { - } \text { Poor maintenance } \\
\text { electrical } \\
\text { appliances and son }\end{array}$ & $\begin{array}{l}\text { From } 20 \\
\text { to } 40 \%\end{array}$ \\
\hline
\end{tabular}




\section{Note:}

The quantification of the probability coefficients, attributed to the different categories of items which can be the cause of fire is given arbitrarily (but respecting a certain sense). The system which we want to establish, through our research, will be strengthened by an initial quantification, more appropriate, following the results of simulation expertise and a lot of experience.

\section{BAYESIAN METHODS}

After the step of assigning probability coefficients, we will see how to apply the Bayesian approach to develop a first mathematical model in order to diagnose the fire potential risks.

\subsection{Comparative study}

In order to choose an efficient techniques from artificial intelligence which can be used to manage the risk of fire, we found in the literature a comparative study [8] which showed the benefits of Bayesian networks in different used cases as acquisition, representation and use compared to other methods for the resolution of some problems as shown in the following table.

Table 2 : Comparative Study of Artificial Intelligence Techniques

\begin{tabular}{|c|c|c|c|c|}
\hline Knowledge & $\begin{array}{c}\text { Neurol } \\
\text { networks }\end{array}$ & $\begin{array}{c}\text { Decision } \\
\text { tree }\end{array}$ & $\begin{array}{c}\text { Expert } \\
\text { systems }\end{array}$ & $\begin{array}{l}\text { Bayesian } \\
\text { networks }\end{array}$ \\
\hline \multicolumn{5}{|l|}{ Acquisition } \\
\hline Expertise & & & $*$ & \\
\hline Data only & $*$ & + & & + \\
\hline Mixed & + & + & & $*$ \\
\hline Incremental & + & & & $*$ \\
\hline Generalization & $*$ & + & & + \\
\hline $\begin{array}{c}\text { Incomplete } \\
\text { data }\end{array}$ & + & & & $*$ \\
\hline \multicolumn{5}{|l|}{ Representation } \\
\hline Uncertainty & & & + & $*$ \\
\hline Readability & & + & + & $*$ \\
\hline Ease & + & $*$ & & \\
\hline Homogeneity & & & & $*$ \\
\hline \multicolumn{5}{|l|}{ Use } \\
\hline $\begin{array}{c}\text { queries } \\
\text { developed }\end{array}$ & & & + & $*$ \\
\hline $\begin{array}{l}\text { economic } \\
\text { utility }\end{array}$ & + & & & $*$ \\
\hline Performance & $*$ & & & \\
\hline
\end{tabular}

The signe + means that the technique is less appropriate. The signe * means that this technique is more appropriate.

\subsection{Bayes equation}

Two events are A and B are conditionally independent in a context c, the Bayes theorem can be represented as follows:

$\mathrm{P}(\mathrm{B} \mid \mathrm{A}, \mathrm{c})=\frac{\mathrm{P}(\mathrm{B} \mid \mathrm{c}) \mathrm{P}(\mathrm{A} \mid \mathrm{B}, \mathrm{c})}{\mathrm{P}(\mathrm{A} \mid \mathrm{c})}$

\section{With:}

$\mathrm{P}(\mathrm{B} \mid \mathrm{A}, \mathrm{c})$ : The posterior probability or probability of B after taking into account the effect of $\mathrm{A}$ in context $\mathrm{c}$.

$\mathrm{P}(\mathrm{A} \mid \mathrm{B}, \mathrm{c})$ : The probability of $\mathrm{A}$ assuming that $\mathrm{B}$ is true in a context $\mathrm{c}$

\subsection{Application of Bayes equation}

We consider:

$\mathrm{X}$ : The event «fire ignition»

A: The event « Existence of an event trigger »

$\mathrm{P}(\mathrm{X})$ : «Fire ignition probability »

$\mathrm{P}(\mathrm{A})$ : « Existence of a triggering event probability »

The trigger event $\mathrm{A}$ can be decomposed into sub trigger events (A1, A2, A3 ... An). And each event in the set (A1, A2, $\mathrm{A} 3, \ldots, \mathrm{An})$ can have a relationship with another sub trigger from the same set.

Following the law of total probability, we have:

$\mathrm{P}(\mathrm{X})=\sum_{\mathrm{i}=1}^{\mathrm{n}} \mathrm{P}(\mathrm{X} \cap \mathrm{Ai})$

After a series of demonstrations, we arrive at the following Bayes theorem to calculate the probability of $\mathrm{X}$ (a fire ignition) knowing that there are several possible triggers events (A1, A2, A3, .... An):

$P(A i \mid X)=\frac{P(A i) P(X \mid A i)}{\sum_{i=1}^{n} P(A i) P(X \mid A i)}$

With:

$\mathrm{P}(\mathrm{Ai} \mid \mathrm{X})$ is the probability of the event $\mathrm{A}$ if we suppose that the event $\mathrm{X}$ is true.

$\mathrm{P}(\mathrm{X} \mid \mathrm{Ai})$ is the probability of $\mathrm{X}$ after taking into account the effect of Ai.

To facilitate the implementation in computer science by programming a single model, we will consider for each trigger event a coefficient $\alpha \mathrm{i}$ witch indicates its existence:

- $\alpha i \neq 0$ if the trigger exists

- $\alpha \mathrm{i}=0$ if not

$\mathrm{P}(\mathrm{Ai})$ becomes $\alpha \mathrm{i} * \mathrm{P}(\mathrm{Ai})(1)$

Similarly, we will consider the factors that can reduce the induced effect of the trigger using the coefficient $\mathrm{Bi}$.

$\mathrm{P}(\mathrm{Ai})$ becomes $\left(1-\sum_{1}^{n} \beta i\right) * \mathrm{P}(\mathrm{Ai})$

By grouping (1) and (2), we obtain the following result:

$\mathrm{P}(\mathrm{Ai})$ becomes $\mathrm{Ci} * \mathrm{P}(\mathrm{Ai})$

$\mathrm{Ci}=0$ if $\alpha \mathrm{i}=0$ or $1-\sum_{1}^{n} \beta i \leq 0$

$\mathrm{Ci} \neq 0$ if $1-\sum_{1}^{n} \beta i>0$

So the total probability of $\mathrm{X}$ (potential fire) knowing that there are several trigger events and other reducers can be expressed as follows:

$\mathrm{P}(\mathrm{Ai} \mid \mathrm{X})=\frac{\mathrm{Ci} * \mathrm{P}(\mathrm{Ai}) \mathrm{P}(\mathrm{X} \mid \mathrm{Ai})}{\sum_{\mathrm{i}=1}^{\mathrm{n}} \mathrm{Ci} * \mathrm{P}(\mathrm{Ai}) \mathrm{P}(\mathrm{X} \mid \mathrm{Ai})}$ 


\subsection{An application example}

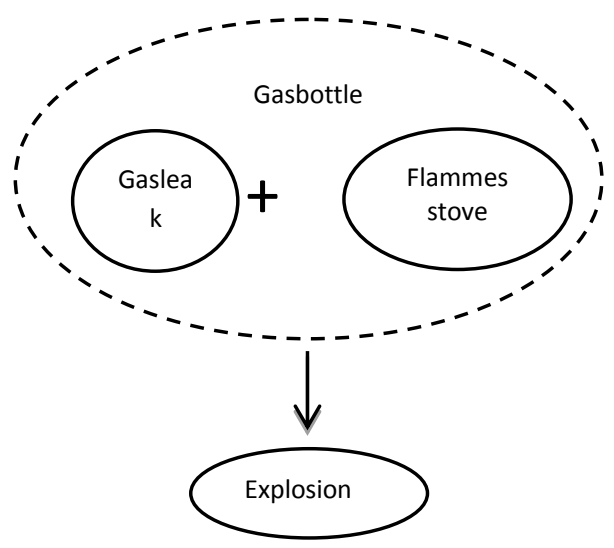

Fig. 3: Process triggering firedue to gas leak

$\mathrm{X}:$ «Fire ignition »

Triggering Events

A1: «Gas leak»

A2 : «Presence of flammable materials »

A3 : «Presence of a short circuit»

\section{Multiplier coefficients (reducers)}

$\beta 1,1$ : «Presence of a fire door in the room »

B1,2: «Presence of an open window in the room»

$\beta 1,3:$ : Presence of alarms (gas detectors) »

\section{Probability calculation:}

Table 3: Attribution of descriptions for probability values

\begin{tabular}{|c|c|}
\hline Probability & Description \\
\hline 0,01 à 0,39 & Low \\
\hline 0,40 à 0,69 & Medium \\
\hline 0,70 à 0,99 & High \\
\hline
\end{tabular}

Table 4: Value assignment probability for trigger events and the multiplier coefficients.

\begin{tabular}{|c|c|}
\hline Event & Probability \\
\hline$A 1$ & Moyenne \\
\hline$A 2$ & Basse \\
\hline$A 3$ & Moyenne \\
\hline$\beta_{2}$ & Basse \\
\hline$\beta_{1}$ & Basse \\
\hline$\beta_{3}$ & Basse \\
\hline
\end{tabular}

Case $N^{\circ} 1$ : Probability of $X$ without the influence of the probability coefficient $\mathrm{Ci}$

According to Bayes' theorem, we can calculate the probability of $\mathrm{X}$ (triggering probability fire due to gas leak)

$$
P(A 1 \mid X)=\frac{P(A 1) P(X \mid A 1)}{P(A 1) P(X \mid A 1)+P(A 2) P(X \mid A 2)+P(A 3) P(X \mid A 3)}
$$

A.N:

$\mathrm{P}(\mathrm{A} 1)=0.4, \mathrm{P}(\mathrm{A} 2)=0.3, \mathrm{P}(\mathrm{A} 3)=0.4$

$\mathrm{P}(\mathrm{X} \mid \mathrm{A} 1)=0.2, \mathrm{P}(\mathrm{X} \mid \mathrm{A} 2)=0.3, \mathrm{P}(\mathrm{X} \mid \mathrm{A} 3)=0,4$ $\underline{\text { So }}$

$P(A 1 \mid X)=0,24$

Case $\mathrm{N}^{\circ} 2$ : Probability of $\mathrm{X}$ under the influence of probabilistic coefficient $\mathbf{C i}$

Calculate the probability of $\mathrm{X}$ (triggering probability fire due to gas leak) in the presence of coefficient $\mathrm{Ci}$.

$$
\begin{aligned}
& P(A 1 \mid X)=\frac{C 1 * P(A 1) * P(X \mid A 1)}{\sum_{1}^{3} C i * P(A i) * P(X \mid A i)} \\
& P(A 1 \mid X) \\
& =\frac{C 1 * P(A 1) P(X \mid A 1)}{C 1 * P(A 1) P(X \mid A 1)+C 2 * P(A 2) P(X \mid A 2)+C 3 * P(A 3) P(X \mid A 3)} \\
& \mathrm{P}(\mathrm{A} 2)=0.3, \mathrm{P}(\mathrm{A} 3)=0.4, \mathrm{P}(\mathrm{A} 1)=0,4 \\
& \mathrm{P}(\mathrm{X} \mid \mathrm{A} 1)=0.2, \mathrm{P}(\mathrm{X} \mid \mathrm{A} 2)=0.3, \mathrm{P}(\mathrm{X} \mid \mathrm{A} 3)=0,4 \\
& \alpha 1=\alpha 2=\alpha 3=1 \text { (all triggers are present }) \\
& \beta 1,1=0.2, \beta 1,2=0.1, B 1,3=0,2
\end{aligned}
$$

$\sum_{1}^{n} \beta 2, i=0$ (Absence of the reducing elements forA2)

$\sum_{1}^{m} \beta 3, i=0$ (Absence of the reducing elements for $\mathrm{A} 3$ )

Therefore:

$$
\begin{aligned}
& \mathrm{C} 2=1-\sum_{1}^{n} \beta 2, i=1 \\
& \mathrm{C} 3=1-\sum_{1}^{m} \beta 3, i=1 \\
& \mathrm{C} 1=1-\sum_{1}^{3} \beta 1, i \\
& =1-\beta 1,1-\beta 1,2-\beta 1,3 \\
& =0,5
\end{aligned}
$$

So:

$$
P(A 1 \mid X)=0,13
$$

According to the result, there is a decrease in probability of 0.24 to 0.13 when introducing reducing elements.

\section{Results Analysis:}

In the first case, we calculated the probability of $X$ without the influence of the probability coefficient $\mathrm{Ci}$.

And in the second one, we calculated the probability of $\mathrm{X}$ under the influence of probabilistic coefficient $\mathrm{Ci}$

We can resume the resultants obtained in the follow table:

Table 5: Probability of fire ignition under the influence of probabilistic coefficient $\mathrm{Ci}$

\begin{tabular}{|c|c|}
\hline Case & Probability \\
\hline WithCi & $13 \%$ \\
\hline Without Ci & $24 \%$ \\
\hline
\end{tabular}

As a result, we observe that the probability of fire ignition is more important in the presence of the probabilistic coefficient $\mathrm{Ci}$ (presence of elements triggers), and less important in the opposite case. 
In the following graph, we present the variation of triggering probability fire based on the number of triggers and depending on the presence or absence of the reducing elements.

\section{Without reduction factors}

$\mathrm{P}(\mathrm{A} 1 \mid \mathrm{X})=1$ (it is the only existing trigger so the fire was necessarily triggered because the event A1)

$\mathrm{P}(\mathrm{A} 1 \mid \mathrm{X})=0,47$ (by applying Bayes rule with presence of another trigger event A2)

$\mathrm{P}(\mathrm{A} 1 \mid \mathrm{X})=0,24$ (by applying the Bayes equation en presence of two other events trigger $\mathrm{A} 2$ and $\mathrm{A} 3$ )

\section{With reduction factors}

$\mathrm{P}(\mathrm{A} 1 \mid \mathrm{X})=1$

$\mathrm{P}(\mathrm{A} 1 \mid \mathrm{X})=0,15($ en presence of $\mathrm{A} 1$ and $\mathrm{A} 2)$

$\mathrm{P}(\mathrm{A} 1 \mid \mathrm{X})=0,13($ en presence of $\mathrm{A} 1, \mathrm{~A} 2$ and $\mathrm{A} 3)$

\section{Comparative graph}

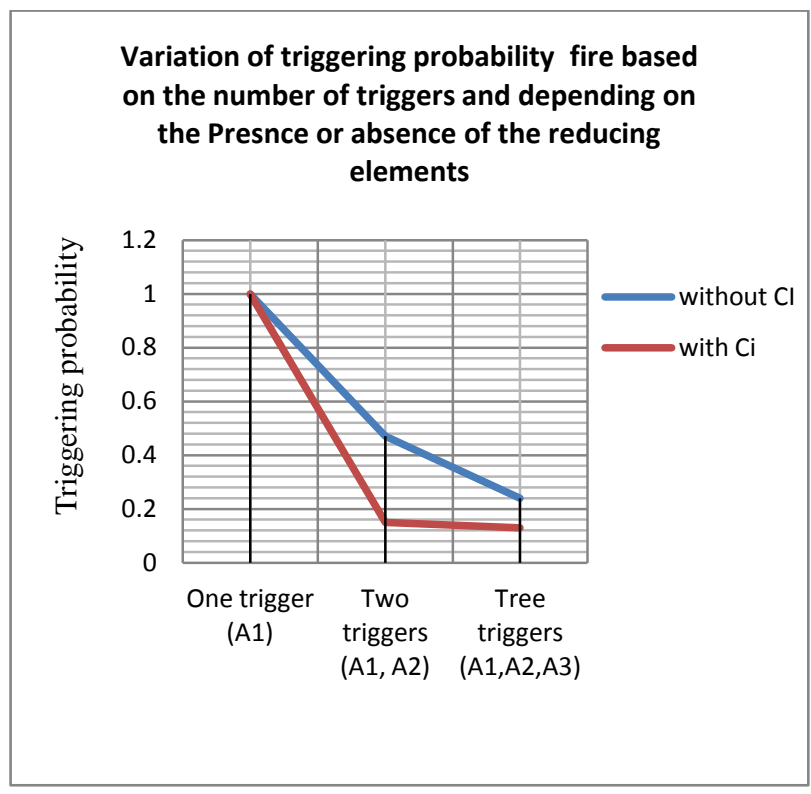

\section{Note:}

As a reminder, the attribution of initial values for the initiating events and reducing elements are attributed according to a logic which respects the right direction. As this work should be integrated into a computing tool that will include automatic learning module provides automatic self-regulation for an optimal decision.

\section{CONCLUSION AND PERSPECTIVES}

In the foregoing, a method has been proposed based on Bayes theory in order to extract an equation that will allow us to model the diagnostic study of the fire risk.
To be complete, our method must cover two stages of its process, not included in this article, and requires computer processing including:

- The development of result based on the parameters in each case study: consider the triggers fire and the presence of objects that can reduce potential risks.

- The implementation of learning techniques to correct the default values assigned using concrete simulations.

These two steps will be communicated and will be later enriched by other techniques from artificial intelligence as a constraint programming, fuzzy logic and neural networks which we will develop in future papers.

\section{REFERENCES}

[1] Smet Erik, FireRiskAssessmentMethod For Engineering, D/1996, Deuxièmeédition 1999

[2] Dubois-Maury Jocelyne, Un risque urbain permanent : l'incendie. In: Annales de Géographie. 1988, t. 97, n539.

[3] ALEKSANDER, I. Introduction à la conception des systèmes intelligents. Paris (Fr.) :Hermès, 1985. 165 p.

[4] Kevin Roebuck, Saas - Software As a Service: HighImpact Emerging Technology - What You Need to Know: Definitions, Adoptions, Impact, Benefits, Maturity, Vendors, Emereo Pty Limited 30 mai 2011.

[5] R.G. Cowell \& al. (Springer Verlag), Probabilistic Networks and Expert Systems -

[6] RAULT, J.C. Les systèmes experts : perspectives industrielles. Bulletin de liaison de la recherche en informatique et automatique, 1984. No.97.

[7] Bruno Bouzy, Réseaux Bayésiens, 26 février 2008

[8] P. Naïm, P.H. Wuillemin, Ph. Leray, O. Pourret, A. Becker (Eyrolles), Les Réseaux Bayésiens.

[9] Véronique Delcroix, Mohamed-Amine Maalej, Sylvain Piechowiak, Les Réseaux Bayésiens versus d'autres modèles probabilistes pour le diagnostic multiple de systèmes complexes.

[10]Jean-Michel d'HOOP, Sécurité incendie bâtiment,Référence SE2050 | Date de publication : 10 avr. 2002.

[11]GRANDJEAN, P. JOUVE, P. La sécurité incendie dans les bâtiments recevant du public. Paris (Fr.) : Editions du Moniteur, 1984. 224 p. 